Research paper

\title{
A Cycloalkanol from Derivatization Studies on Vanillin: Evaluation of Antioxidant Activity of Obtained Derivatives
}

Olawale Hakeem Oladimeji ${ }^{1, *}$, Ekemini Samuel Idiong ${ }^{1}$, Udeme Akpan Joseph ${ }^{1}$, Victor Udo Anah ${ }^{1,}$, Moji Taibat Bakare-Odunola ${ }^{2}$,Stanllinus Njinga ${ }^{2}$, and Saad Toyin Abdullahi ${ }^{2}$

${ }^{1}$ Department of Pharmaceutical \& Medicinal Chemistry, Faculty of Pharmacy, University of Uyo, Uyo, Nigeria

${ }^{2}$ Department of Pharmaceutical \& Medicinal Chemistry, Faculty of Pharmaceutical Sciences, University of Ilorin, Nigeria

\section{ARTICLE INFO}

Received 26 December 2021

Revised 28 January 2022

Available Online 15 February 2022

ACADEMIC EDITOR

Dr. Mohamad Taleuzzaman

\section{*CORRESPONDING AUTHOR}

Dr. Olawale Hakeem Oladimeji, Department of Pharmaceutical \& Medicinal Chemistry, Faculty of Pharmacy, University of Uyo, Uyo, Nigeria

\section{ABSTRACT}

Background: Vanillin is a white monoclinic crystalline compound whose chemical nomenclature is p-hydroxy-m-methoxy benzaldehyde. It is a phenolic aldehyde with a pleasant flavor and popularly found in vanilla beans and roasted coffee amongst many other sources. It serves as in addition; it possesses antitumor and particularly antioxidant activity which formed the essence of this study.

Objectives: The insidious presence of free oxygenated and nitrogen radicals in the human body has become a worrisome concern. These chemical species continue to plague the human cells, tissues and organs resulting in different pathophysiological conditions such as cancers and neurodegenerative disorders like Alzheimer's disease and Parkinson's disease amongst many other ailments. The search for novel pharmacological compounds with the aim of curbing the rising incidence of these radicals led the choice of vanillin in this present study.

Methodology: Vanillin was separately subjected to a series of derivatization reactions namely, acetylation, $O$-demethylation, reduction and oxidation. The melting points, refractive indices and optical rotations of the lead compound and derivatives were obtained. The antioxidant activities of the five compounds were determined using the DPPH (2, 2-diphenyl-1picrylhydrazyl hydrate) test. Comparison of the obtained antioxidant activities was done to determine if any improvements could be seen in the derivatives.

Results: The identities of the derivatives have been revealed to be vanillyl acetate (E-1) (acetyl derivative), 3, 4-dihydroxy benzaldehyde or protocatechui aldehyde (E-2) (demethylated derivative), o-methoxy-pmethyl cyclohexan-1-ol (J-1) (reduced derivative) and vanillic acid (J-2) (oxidized derivative) respectively using the IR spectral technique. Vanillin, E-2 and J-2 derivatives gave marginal antioxidant activity of IC50 of $0.81,0.84$ and $0.0 .85 \mu \mathrm{g} / \mathrm{mL}$ respectively while $J-1$ and $E-1$ demonstrated moderately significant IC50 of 0.59 and $0.63 \mu \mathrm{g} / \mathrm{mL}$ which compare favorably with $0.44 \mu \mathrm{g} / \mathrm{mL}$ elicited by Vitamin $C$ (a standard antioxidant drug). It is pertinent to point out that the obtained reduced derivative is a substituted cycloalkanol (a saturated cyclic compound) instead of a substituted phenolic compound as was expected.

Conclusion: The results from this study indicate that reduction and acetylation separately enhance the antioxidant activity of vanillin. 
Keywords: Vanillin; Vanillyl acetate; Protocatechui aldehyde; o-methoxyp-methyl cyclohexan-1-ol; Vanillic acid; Antioxidant activity

\section{Introduction}

Oxidative stress is linked to the imbalance between reactive oxygen species and reactive nitrogen species (ROS and RNS) production and antioxidant defense, leading to oxidative damage to lipids, proteins and genetic material that contributes to the development of a range of different patho-physiological conditions [1]. Thus, when the body is unable to process and remove free radicals efficiently, oxidative stress (OS) occurs. This condition has been implicated in a number of disease conditions such as arthritis, atherosclerosis, vision loss, emphysema, respiratory ailments, autoimmune disorders, mental stress, Alzheimer's disease and Parkinson's disease amongst so many others. Some free radicals are needed for the body to function effectively, but their overload may be fatal. The body needs to maintain an equilibrium between free radicals and antioxidants so as to prevent oxidative stress. Hence, the need for efficient antioxidants cannot be over emphasized. In the search for novel pharmacologically active compounds, vanillin was considered. Vanillin is a pleasant-smelling aromatic compound occurring naturally in vanilla beans, roasted coffee, Chinese red pine and leptotes amongst many other sources. It is used as a flavoring agent in candies, ice cream, yoghurt, beverages, soda drinks, confectioneries and alcoholic liquors. In addition, it has tremendous applications in the fragrance and perfumery industries where it is used as an additive in making candles, incense, air-fresheners, creams, soaps, shampoos and ointments. It possesses antioxidant and antitumor properties and is used as a chemical intermediate in the production of pharmaceuticals, cosmetics and herbicides. In this present study, vanillin was subjected to acetylation, O-demethylation, reduction and oxidation reactions. The antioxidant activities $\left(\mathrm{IC}_{50}\right)$ of the vanillin and the respective derivatives were obtained using the rapid bench-top DPPH (2, 2-diphenyl-1-picrylhydrazylhydrate) test [24]. Comparison of the antioxidant activities was done with the aim of determining if any improvements in the obtained activities of the derivatives could be noticed.

\section{Materials and Methods}

\section{Reagents/chemicals}

DPPH (2, 2-diphenyl-1-picryl hydrazyl hydrate), vanillin and vitamin $\mathrm{C}$ tablets were purchased from Tianjin Kernel Chemical Reagent Company, China, Sigma Aldrich Chemicals, Germany and Emzor Pharmaceuticals, Nigeria respectively. Solvents and reagents namely, acetic acid, acetic anhydride, chloroform, di-ethyl ether, dichloromethane, ethanol, ethyl acetate, hydrochloric acid, iodine, magnesium sulphate, methanol, n-butanol, n-hexane, petroleumether, potassium permaganate, pyridine $\mathrm{HCl}$, sodium borohydride, disodium hydrogen phosphate, sodium hydroxide, sulphuric acid and tetrahydrofuran were obtained as AnaLAR Grade Chemicals from BDH Chemicals Limited, Poole, England.

\section{Solubility tests for vanillin}

Vanillin $(0.01 \mathrm{~g})$ was added to $2 \mathrm{~mL}$ of each of the following solvents namely, distilled water, methanol, ethyl acetate, ethanol, petroleum ether, n-hexane, nbutanol, dilute $\mathrm{HCl}$, dilute $\mathrm{H}_{2} \mathrm{SO}_{4}$ separately and observation was made for complete dissolution (solubility) or otherwise.

\section{Determination of melting point}

Vanillin $(0.05 \mathrm{~g})$ was filled to a quarter of the length of a micro-capillary tube and the melting point determined [5] using an Electro-thermal Melting Point apparatus (Electro-thermal Engineering Limited, England).

\section{Synthesis of acetyl derivative}

Vanillin $(0.4 \mathrm{~g})$ was dissolved in a mixture of acetic anhydride $(10 \mathrm{~mL})$ and acetic acid $(10 \mathrm{~mL})$ in a beaker. The solution was heated for 20 minutes and allowed to cool. Concentrated sulphuric acid $(5 \mathrm{~mL})$ was added as catalyst. Further heating was done for a few minutes. The mixture was covered with aluminum foil and kept in the refrigerator. After two weeks, an amorphous compound was formed in the beaker. $5 \mathrm{~mL}$ of warmed di-ethyl was added and the mixture warmed again for some minutes. The compound dissolved on warming but formed back after four hours, filtered, dried and then stored in the refrigerator for further studies $[6,7]$. 
<smiles>CC(=O)OCc1cc(C=O)ccc1O</smiles>

Vanillin

\section{O-demethylation reaction}

Vanillin $(0.4 \mathrm{~g})$ was added to a solution pyridine $\mathrm{HCl}$ $(50 \mathrm{~mL})$ and dilute hydrochloric acid $(10 \mathrm{~mL})$ and the<smiles>COc1cc(C=O)ccc1OC(C)=O</smiles>

Vanillin acetate or vanillyl acetate (E-1) mixture stirred until complete dissolution. The mixture was heated at $27^{\circ} \mathrm{C}$ for thirty minutes and allowed to cool. The resulting product was filtered, dried at water pump and then stored in a refrigerator [8].<smiles>COc1cc(Cl)ccc1O</smiles>

Vanillin

\section{Synthesis of reduced derivative}

A solution of vanillin $(1.5 \mathrm{~g})$ in tetrahydrofuran $(20 \mathrm{~mL})$ was slowly added to a suspension of sodium borohydride $(0.45 \mathrm{~g})$ in tetrahydrofuran $(200 \mathrm{~mL})$ at room temperature and left for ten minutes. The mixture was then stirred until evolution of gas ceased. Iodine $(0.63 \mathrm{~g})$ and tetrahydrofuran $(20 \mathrm{~mL})$ were added slowly
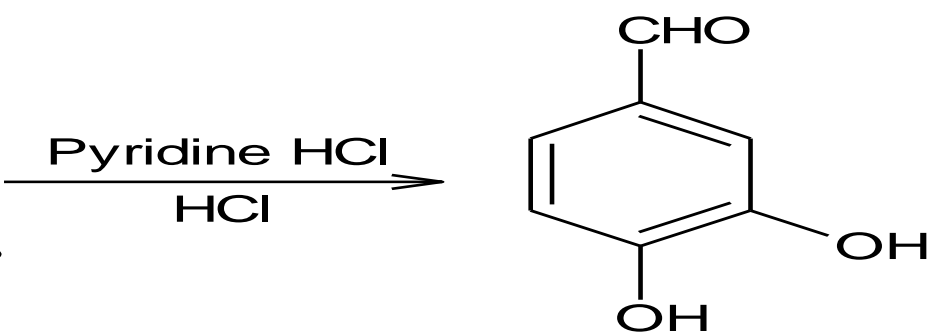

3, 4-dihydroxy benzaldehyde or protocatechui aldehyde (E-2) to the mixture at a temperature of $0{ }^{\circ} \mathrm{C}$ (in ice) with further evolution of hydrogen gas. The contents were further stirred for 1 hour. Dilute hydrochloric acid (5 $\mathrm{mL}$ ) was added carefully and the mixture extracted with diethyl ether. The combined ethereal extract was washed with $3 \mathrm{M}$ sodium hydroxide $(30 \mathrm{~mL})$, brine and dried over magnesium sulphate. Evaporation of the organic layer gave the reduced product [9].<smiles>COc1cc(C=O)ccc1O</smiles>

Vanillin

\section{Synthesis of oxidized derivative}

Vanillin ( $0.4 \mathrm{~g})$ was weighed and added to a butanolic solution of potassium permanganate $(50 \mathrm{~mL})$ and the

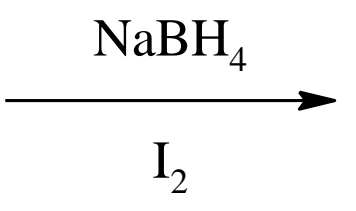<smiles>COC1CC(C)CCC1O</smiles>

o-methoxy-p-methyl cyclohexan-1-ol (J-1)

mixture stirred for ten minutes. Disodium hydrogen phosphate $(5 \mathrm{~mL})$ was added as a buffer to the mixture which was stirred for thirty (30) minutes and then stored in the refrigerator for a week for complete reaction [8]. 


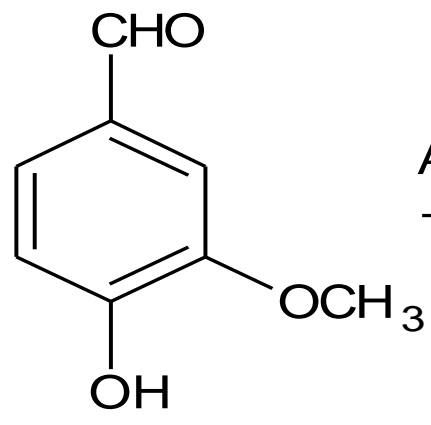

Vanillin
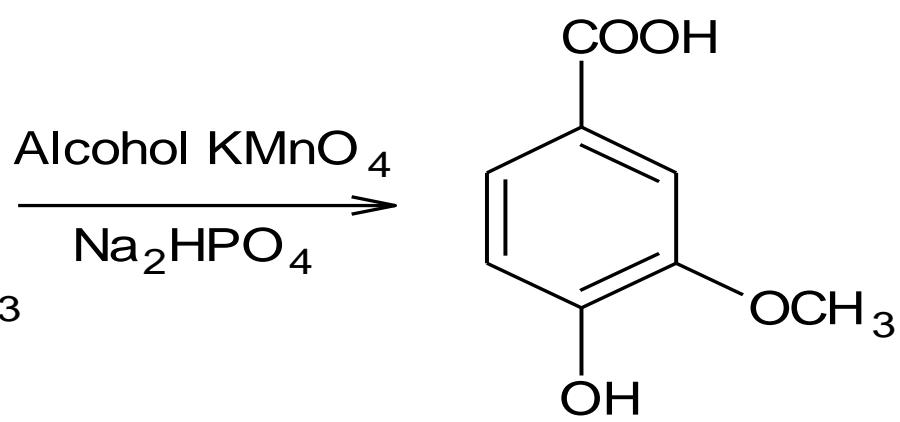

3-methoxy-4-hydroxy benzoic acid or vanillic acid (J-2)

\section{Determination of specific optical rotation and refractive index}

Each sample $(0.05 \mathrm{~g})$ was dissolved in methanol (10 $\mathrm{mL}$ ). The tube of the Polarimeter (ADP-220, Bellingham Stanley, England) was filled with distilled water and the machine subsequently zeroed. The tube was refilled with $5 \mathrm{~mL}$ of sample and the optical rotation and was measured at the wavelength $(\lambda)$ of sodium $D$ line $(589.3 \mathrm{~nm})$ at $20.5^{\circ} \mathrm{C}$. Similarly, the refractive index of sample was obtained on a refractometer (WAY-15, Abbe, England) at the wavelength $(\lambda)$ of sodium D line $(589.3 \mathrm{~nm})$ at $20.5{ }^{\circ} \mathrm{C}[10,11]$. In a situation where the derivative was a liquid, $5 \mathrm{~mL}$ of sample was used for the determinations.

\section{Antioxidant activity}

Spectrophotometric determination of antioxidant activity using DPPH reagent

Substances which are capable of donating electrons or hydrogen atoms can convert the purple-colored DPPH radical (2, 2-diphenyl-1-picrylhydrazyl hydrate) to its yellow-colored non-radical form; 1, 1-diphenyl-2-picryl hydrazine $[12,13]$. This reaction can be monitored by spectrophotometry.

\section{Preparation of calibration curve for DPPH reagent}

DPPH (4 mg) was weighed and dissolved in methanol $(100 \mathrm{~mL})$ to produce the stock solution $(0.004 \% \mathrm{w} / \mathrm{v})$. Serial dilutions of the stock solution were then carried out to obtain the following concentrations: 0.0004, $0.0008,0.0012,0.0016,0.0020,0.0024,0.0028,0.0032$ and $0.0036 \% \mathrm{w} / \mathrm{v}$. The absorbance of each of the sample was taken at $\lambda_{\mathrm{m}} 512 \mathrm{~nm}$ using the Ultra-Violet Spectrophotometer (Jenway 6405, USA). This machine was zeroed after an absorbance had been taken with a solution of methanol without DPPH which served as the blank.

\section{Determination of the antioxidant activity of vanillin, derivatives and vitamin $\mathrm{C}$}

$2 \mathrm{mg}$ each of sample was dissolved in $50 \mathrm{~mL}$ of methanol. Serial dilutions were carried out to obtain the following concentrations: $0.0004 \mathrm{mg} \mathrm{mL}^{-1}, 0.0008 \mathrm{mg}$ $\mathrm{mL}^{-1}, 0.0012 \mathrm{mg} \mathrm{mL}^{-1}, 0.0016 \mathrm{mg} \mathrm{mL}^{-1}$ and $0.0020 \mathrm{mg}$ $\mathrm{mL}^{-1}$ using methanol. $5 \mathrm{~mL}$ of each concentration was incubated with $5 \mathrm{~mL}$ of $0.004 \%$ w/v methanolic DPPH solution for optimal analytical accuracy. After an incubation period of 30 minutes in the dark at room temperature $\left(25 \pm 2^{0} \mathrm{C}\right)$, observation was made for a change in the color of the mixture from purple to yellow. The absorbance of each of the samples was then taken at $\lambda_{\mathrm{m}} 512 \mathrm{~nm}$. The Radical Scavenging Activity (RSA $\%$ ) or Percentage Inhibition (PI \%) of free radical DPPH was thus calculated:

$$
R S A \%(P I \%)=\left[\left(\mathrm{A}_{\text {blank }}-A_{\text {sample }}\right) / \mathrm{A}_{\text {blank }}\right] \times 100
$$

$A_{\text {blank }}$ is the absorbance of the control reaction (DPPH solution without the test sample and $\mathrm{A}_{\text {sample }}$ is the absorbance of DPPH incubated with the sample. Vanillin /derivative / Vitamin C concentration providing $50 \%$ inhibition $\left(\mathrm{IC}_{50}\right)$ was calculated from a graph of inhibition percentage against the concentration of the vanillin/ derivative /vitamin C [14-16]. Vitamin $\mathrm{C}$ was used as a standard antioxidant drug.

\section{Thin-layer chromatography of samples}

A portion of each solid sample $(0.05 \mathrm{~g})$ dissolved in methanol $(2 \mathrm{~mL})$ or $2 \mathrm{~mL}$ of liquid sample was applied on a $20 \mathrm{~cm} \times 10 \mathrm{~cm}$ silica gel analytical plate (Merck, Germany) and then developed in a toluene : acetone : water (10:20:1) mixture in a chromatographic tank until optimal separation was observed. The retardation factor $\left(\mathrm{R}_{\mathrm{F}}\right)$ was then computed thus: 
Citation: Oladimeji OH, Idiong ES, Joseph UA, et al. A Cycloalkanol from Derivatization Studies on Vanillin: Evaluation of Antioxidant Activity of Obtained Derivatives. J Pharm Res Sci Technol 2022; 6(1): 157. doi: $\underline{10.31531 / j p r s t .1000157}$

$\mathbf{R}_{\mathbf{F}}=$ distance moved by spot distance moved by solvent front

\section{Infra-red spectroscopy of samples}

Each sample $(0.2 \mathrm{~g})$ or $2 \mathrm{~mL}$ (liquid) was analyzed for IR characteristics using the FTIR 84005 Spectrophotometer (Shimadzu, Japan).

\section{Ultra-violet/visible spectroscopy of samples}

A portion of each sample ( $0.2 \mathrm{~g})$ or $2 \mathrm{~mL}$ (liquid) was analyzed for UV/VS absorption characteristics using the Jenway 6405 UV/VS Spectrophotometer.

\section{Results}

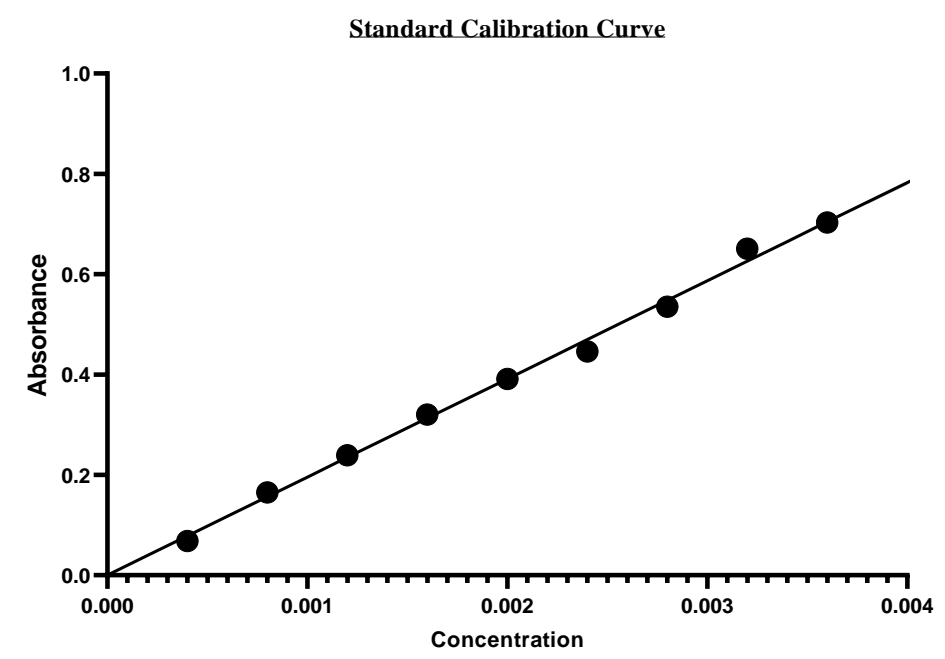

Figure 1: Graph of absorbance against concentration of methanolic solution of DPPH reagent.

Table 2: Absorbance of samples incubated with DPPH at different concentrations at $\lambda$ max $512 \mathrm{~nm}$ (Blank absorbance of $0.004 \%$ methanolic DPPH reagent: 0.748).

\begin{tabular}{|c|c|c|c|}
\hline Sample & $0.0008 \mathrm{mg} \mathrm{mL}^{-1}$ & $0.0016 \mathrm{mg} \mathrm{mL}^{-1}$ & $0.0024 \mathrm{mg} \mathrm{mL}^{-1}$ \\
\hline Vitamin C & 0.061 & 0.053 & 0.052 \\
\hline Vanillin & 0.325 & 0.32 & 0.275 \\
\hline E-1 & 0.307 & 0.223 & 0.164 \\
\hline E-2 & 0.395 & 0.351 & 0.304 \\
\hline $\mathrm{J}-1$ & 0.259 & 0.189 & 0.146 \\
\hline $\mathrm{J}-2$ & 0.391 & 0.349 & 0.301 \\
\hline
\end{tabular}

Key: E-1 = Vanillin acetate or vanillyl acetate or 4-O-acetyl vanillin); E-2 = 3, 4-dihydroxy benzaldehyde (Protocatechui aldehyde); J-1 = o-methoxy-p-methyl cyclohexan-1-ol; J-2 = 3-methoxy-4-hydroxy benzoic acid (vanillic acid); DPPH = 2, 2-Diphenyl-1-picryhydrazyl hydrate. 
Citation: Oladimeji OH, Idiong ES, Joseph UA, et al. A Cycloalkanol from Derivatization Studies on Vanillin: Evaluation of Antioxidant Activity of Obtained Derivatives. J Pharm Res Sci Technol 2022; 6(1): 157. doi: 10.31531/jprst.1000157

Table 3: Radical scavenging activity (percentage inhibition \%) of samples at different concentrations and $\mathrm{IC}_{50}$ of samples.

\begin{tabular}{|l|r|r|r|c|}
\hline Sample & $\mathbf{0 . 0 0 0 8 ~} \mathbf{~ m g ~ m L - 1}$ & $\mathbf{0 . 0 0 1 6} \mathbf{~ m g ~ m L - 1}$ & $\mathbf{0 . 0 0 2 4} \mathbf{~ m g ~ m L - 1}$ & IC $_{\mathbf{5 0}}\left(\boldsymbol{\mu g m L}^{\mathbf{- 1}}\right)$ \\
\hline Vitamin C & 91.84 & 92.91 & 93.05 & 0.44 \\
\hline Vanillin & 52.69 & 53.27 & 59.83 & 0.81 \\
\hline E-1 & 58.96 & 70.19 & 78.07 & 0.68 \\
\hline E-2 & 47.19 & 53.41 & 59.41 & 0.84 \\
\hline J-1 & 65.37 & 74.73 & 80.48 & 0.59 \\
\hline J-2 & 52.76 & 55.43 & 57.87 & 0.85 \\
\hline
\end{tabular}

Key: Refer to Table 2 and RSA \% (PI \%) = Radical Scavenging Activity (Percentage Inhibition \%); IC50 = Concentration at which $50 \%$ of DPPH is scavenged or inhibited

Vanillin: $\mathrm{C}_{8} \mathrm{H}_{8} \mathrm{O}_{3}$; mol. wt. $(152.15 \mathrm{~g} / \mathrm{mol})$; white crystalline solid; m.pt. $\left(80-82{ }^{0} \mathrm{C}\right) ;[\mathrm{n}]_{\mathrm{D}}{ }^{20}(1.5770)$; $[\alpha]_{\mathrm{D}}^{20}\left(0^{0}\right) ; \lambda_{\max }(246 \mathrm{~nm}) ; \mathrm{R}_{\mathrm{F}}(0.66) ;$ FTIR $\left(\mathrm{cm}^{-1}\right): 1146$ (C-O-C), 1575 (Ar-C=C), $1634(\mathrm{C}=\mathrm{O}), 2847 \quad(-\mathrm{CH}$ stretching) and 3179 (Ar-OH).

Vanillin acetate or vanillyl acetate (E-1): $\mathrm{C}_{10} \mathrm{H}_{10} \mathrm{O}_{4}$; mol. wt. (194.19 g/mol); amorphous dark yellow solid; m.pt. $\left(79-81{ }^{0} \mathrm{C}\right) ;[\mathrm{n}]_{\mathrm{D}}{ }^{20}(1.5791) ;[\alpha]_{\mathrm{D}}{ }^{20}\left(0^{0}\right), \lambda_{\max }(400$ $\mathrm{nm}) ; \mathrm{R}_{\mathrm{F}}(0.70)$; FTIR $\left(\mathrm{cm}^{-1}\right)$ : 1157 (C-O-C), 1597 (Ar$\mathrm{C}=\mathrm{C}), 1684\left(\mathrm{C}=\mathrm{O}\right.$ in $\left.-\mathrm{COCH}_{3}\right), 1745(\mathrm{C}=\mathrm{O}), 2942(-$ $\mathrm{CH})$ and $2965(-\mathrm{CH})$.

3, 4-dihydroxy benzaldehyde (protocatechui aldehyde (E-2): $\mathrm{C}_{7} \mathrm{H}_{6} \mathrm{O}_{3}$; mol. wt. (138.12 g/mol); pale yellow resinoid compound; m.pt. $\left(152-154{ }^{\circ} \mathrm{C}\right),[\mathrm{n}]_{\mathrm{D}}{ }^{20}$ (1.4874); $[\alpha]_{\mathrm{D}^{20}}\left(0^{0}\right) ; \lambda_{\max }(246 \mathrm{~nm}) ; \mathrm{R}_{\mathrm{F}}(0.23) ;$ FTIR $\left(\mathrm{cm}^{-1}\right)$ : $1600(\mathrm{Ar}-\mathrm{C}=\mathrm{C}), 1756(\mathrm{C}=\mathrm{O}), 3245(-\mathrm{OH})$ and $3487(-\mathrm{OH})$.

o-methoxy-p-methyl cyclohexan-1-ol (J-1): $\mathrm{C}_{8} \mathrm{H}_{16} \mathrm{O}_{2}$; mol. wt. (144.14 g/mol); colorless liquid; [n $]_{\mathrm{D}}{ }^{20}$ (1.5773); $[\alpha]_{\mathrm{D}^{20}}\left(0^{0}\right) ; \lambda_{\max }(370 \mathrm{~nm}) ; \mathrm{R}_{\mathrm{F}}(0.89)$; FTIR $\left(\mathrm{cm}^{-1}\right): 1161(\mathrm{C}-\mathrm{O}-\mathrm{C})$ and $3460(-\mathrm{OH})$.

3-methoxy-4-hydroxy benzoic acid (vanillic acid) (J2): $\mathrm{C}_{8} \mathrm{H}_{8} \mathrm{O}_{4}$; mol. wt. (168.14 g/mol); light yellow solid; m.pt. $\left(209-211^{0} \mathrm{C}\right),[\mathrm{n}]_{\mathrm{D}}{ }^{20}(1.5773) ;[\alpha]_{\mathrm{D}}{ }^{20}\left(0^{0}\right) ; \lambda_{\max }$ $(248 \mathrm{~nm}) ; \mathrm{R}_{\mathrm{F}}(0.53)$; FTIR $\left(\mathrm{cm}^{-1}\right): 1610(\mathrm{Ar}-\mathrm{C}=\mathrm{C}), 1716$ $(\mathrm{C}=\mathrm{O}), 2991(-\mathrm{CH})$ and $3490(-\mathrm{OH})$.

\section{Discussion}

Vanillin is a white monoclinic crystalline compound with sweet smelling, pleasant and balsamic fragrance. It was put through some monographic determinations in this study where its identity, purity, integrity and suitability were established. The compound was observed to be soluble in ethanol, ethyl acetate, nbutanol, n-heaxane, methanol and water when heated.
However, it was insoluble in petroleum ether, dilute hydrochloric acid and dilute sulphuric acid. Its determined melting point and refractive index fall within standard literature values. The UV absorption at $\lambda_{\max }(246 \mathrm{~nm})$ is indicative of the presence of electron densities in $\mathrm{Ar}-\mathrm{C}=\mathrm{C}, \quad-\mathrm{OH}, \quad-\mathrm{OCH}_{3}$ and $\mathrm{HC}=\mathrm{O}$ chromophores while retardation factor $\mathrm{R}_{\mathrm{F}}(0.66)$ shows that vanillin is moderately polar and hence likewise retarded on the silica gel used in the thin-layer chromatographic (TLC) analyses. The IR spectral matrix of vanillin shows stretching's at 1146, 1575, 1634, 2847 and $3179 \mathrm{~cm}^{-1}$ which are diagnostically characteristic of $-\mathrm{C}-\mathrm{O}-\mathrm{C}, \mathrm{Ar}-\mathrm{C}=\mathrm{C},-\mathrm{C}=\mathrm{O},-\mathrm{CH}$ and $\mathrm{Ar}-$ $\mathrm{OH}$ groups respectively. Vanillin acetate or vanillyl acetate or 4-O acetyl vanillin (E-1) which belongs to a class of aromatic phenol esters was synthesized as dark yellow compound with a flavor and fragrance similar to the odour of vanilla. The UV absorption at $\lambda_{\max }(400 \mathrm{~nm})$ which is comparatively higher than that of the parent analogue (vanillin) indicates the presence of electron clouds over $\mathrm{Ar}-\mathrm{C}=\mathrm{C},-\mathrm{OCH}_{3},-\mathrm{OCOCH}_{3}$ and $\mathrm{HC}=\mathrm{O}$ chemical species while retardation factor $\mathrm{R}_{\mathrm{F}}(0.70)$ shows that acetyl product is comparably non-polar and hence weakly retarded on the silica gel plate. The IR spectrum of E-1 shows stretching's at 1157, 1597, 1684, 1745,2942 and $2965 \mathrm{~cm}^{-1}$ which are characteristic of $\mathrm{C}-\mathrm{O}-\mathrm{C}, \mathrm{Ar}-\mathrm{C}=\mathrm{C},-\mathrm{CO}$ in $\mathrm{OCOCH}_{3}$ substitution of the derivative), $-\mathrm{C}=\mathrm{O}$ and $-\mathrm{CH}$ respectively. It is instructive to note that the peaks in the acetyl product absorb at slightly higher than that those recorded in the IR spectrum of vanillin. Furthermore, the peak representing -C-O-C is particularly and diagnostically elucidative indicating that the hydrogen atom in the $\mathrm{OH}$ had been replaced with $-\mathrm{COCH}_{3}$ showing the acetylation of the vanillin had truly taken place. The Odemethylated product (3,4-dihydroxy benzaldehyde) (E-2) was synthesized as a pale-yellow resin. In addition, the UV absorption at $\lambda_{\max }(246 \mathrm{~nm})$ is the same as found with vanillin. However, the electrons are found 
delocalized over only $\mathrm{Ar}-\mathrm{C}=\mathrm{C},-\mathrm{OH}$ and $\mathrm{HC}=\mathrm{O}$ chromophores without $-\mathrm{OCH}_{3}$ while retardation factor $\mathrm{R}_{\mathrm{F}}(0.23)$ indicates that $\mathbf{E}-\mathbf{2}$ is too polar because of the presence of $2-\mathrm{OH}$ groups in the derivative.

Hence, the product is strongly attracted to the $\mathrm{OH}$ groups of the silica gel and thereby making $\mathbf{E}-2$ greatly retarded on chromatographic plate. The IR spectrum of E-2 shows peaks at 1600, 1756, 3245 and $3487 \mathrm{~cm}^{-1}$ which are indicative of $\mathrm{Ar}-\mathrm{C}=\mathrm{C},-\mathrm{C}=\mathrm{O}$ and $-\mathrm{OH}$ chemical species. This derivative also known as protocatechui aldehyde is employed as a perfumery and flavoring agent. In addition, this aldehyde also serves as a precursor in the synthesis of vanillin by biotransformation of cell cultures of Capsicum frutescence [17]. It is also used as an apoptosis inducer in human leukemia cells, possess anti-proliferative property against breast and colorectal cancers and cardio-protective activity [18]. The reduced product (omethoxy-p-methyl cyclohexan-1-ol) (J-1) was synthesized as a colorless liquid. The UV absorption at $\lambda_{\max }(370 \mathrm{~nm})$ is indicative of presence of electrons in $\mathrm{OH}$ and $-\mathrm{OCH}_{3}$ species while $\mathrm{R}_{\mathrm{F}}(0.89)$ shows that the product is non-polar because of the presence of methyl cyclohexyl group thereby making J-1 largely unretarded or un-hindered on the silica-coated plate. The IR spectrum of the derivative shows a matrix characterized by stretchings at 1161 and $3460 \mathrm{~cm}^{-1}$ which are indicative of $-\mathrm{C}-\mathrm{O}-\mathrm{C}$ and $-\mathrm{OH}$ species. It needs to be stated that the reduction reagent $\left(\mathrm{NaBH}_{4} / \mathrm{I}_{2}\right)$ is supposed to selectively reduce the $-\mathrm{C}=\mathrm{O}$ to $-\mathrm{CH}_{2}[9]$. Surprisingly, in addition to this supposition, the three (3) endocyclic $\mathrm{Ar}-\mathrm{C}=\mathrm{C}$ bonds were also reduced. Hence, the IR peaks at 1575 and $1634 \mathrm{~cm}^{-1}$ in the vanillin (parent compound) representing the aromatic double bonds and carbonyl species disappeared. This translates to losses of the aromatic character and carbonyl group in the derivative. This same scenario was observed in a previous study [3] where gallic acid was reduced to a new compound (3,4,5trihydroxycyclohexyl methanol) using $\mathrm{NaBH}_{4} / \mathrm{I}_{2}$. It is interesting to note that if $-\mathrm{C}=\mathrm{O}$ is attached to the aromatic ring, this reduction procedure will result in a product with both $\mathrm{C}=\mathrm{O}$ and $\mathrm{Ar}-\mathrm{C}=\mathrm{C}$ double bonds being reduced simultaneously as has been observed in this present study and [3]. It will be of curious interest to know the reaction mechanism by which this particular reduction is effectuated. However, if the $\mathrm{C}=\mathrm{O}$ is far from the aromatic ring (when not found attached to the aromatic ring), the reduction involves will only the $\mathrm{C}=\mathrm{O}$ and not the $\mathrm{Ar}-\mathrm{C}=\mathrm{C}$ bonds as observed in [2,9]. The oxidation of vanillin led to a compound which has been identified to be vanillic acid (J-2). It is a mono substituted hydroxy benzoic acid which is a plant metabolite and also a conjugate acid of a vanillate. The UV absorption at $\lambda_{\max }(248 \mathrm{~nm})$ highlights the presence of electron clouds over $\mathrm{Ar}-\mathrm{C}=\mathrm{C},-\mathrm{OCH}_{3},-\mathrm{COOH}$ and $\mathrm{OH}$ chemical species while retardation factor $\mathrm{R}_{\mathrm{F}}(0.53)$ indicates that the oxidized product is moderately polar and hence likewise retarded on the silica gel plate. The IR spectrum of this derivative shows peaks at 1610 , 1716, 2991 and $3490 \mathrm{~cm}^{-1}$ reflecting $\mathrm{Ar}-\mathrm{C}=\mathrm{C},-\mathrm{C}=\mathrm{O}$, $\mathrm{CH}$ and $-\mathrm{OH}$ respectively. $\mathbf{J}-2$ has been reported to inhibit inflammatory pains, oxidative stress and cytokine production in mice [19] and serves as an intermediate product in the bioconversion of ferulic acid to vanillin [20]. Generally, the parent compound, vanillin and all other solid derivatives gave melting points and refractive indices which are consistent with literature values. Furthermore, it was observed that vanillin and all the derivatives showed optical rotation $[\alpha]_{\mathrm{D}}^{20}$ of $0^{0}$ indicating that the compounds are optically inactive. Hence, none of these compounds will demonstrate laevorotation (-) (ability of a compound to rotate plane of light in anticlockwise direction) or dextro-rotation (+) (ability of a compound to rotate plane of light in clockwise direction) [10,11]. The preparation of a calibration curve was done for DPPH (2, 2-diphenyl-1-picryl hydrazyl hydrate) reagent with the aim of ascertaining its purity and suitability for use in the antioxidant determinations. The Beer-Lambert's Law is the basis of all absorption spectrophotometry $[12,21]$. The calibration curve obtained indicates that the underlying principles behind the aforementioned law were fulfilled as the curve (Figure 1) shows a straight line which passes through the origin. The reduction of the DPPH radical was determined by taking its absorption at a wavelength of $\lambda_{\mathrm{m}} 512 \mathrm{~nm}$. It was observed that the absorbance of DPPH decreased as the concentration of added free radical scavenger (vanillin /derivative/vitamin C) increased which suggested that the DPPH reagent was being reduced (Table 2). Furthermore,

Table 3 shows radical scavenging activity (RSA \%) or percentage inhibition (PI \%) and the computed $\mathrm{IC}_{50}$ values of vanillin /derivative / vitamin C. The RSA \% is an indicator of the antioxidant activity of vanillin / derivative / vitamin C. Interestingly, vanillin, Odemethylated product (E-2) and oxidized derivative (J2) all demonstrated marginal antioxidant activity $\left(\mathrm{IC}_{50}\right)$ of $0.81,0.84$ and $0.85 \mu \mathrm{g} \mathrm{mL}^{-1}$ respectively. This is not surprising because the chemical structures of these three compound/products contain(s) chemical species such as $-\mathrm{OH}, \mathrm{HC}=\mathrm{O}$ and $/$ or $-\mathrm{COOH}$ which confer some hydrophilic character on the compounds. Hence, these 
compounds will experience some hindrance in reaching the active or allosteric sites where the pharmacological action of anti-oxidation is to be affected. However, the reduced product (J-1) and acetyl product $(\mathbf{E}-\mathbf{1})$ gave moderate antioxidant activity $\left(\mathrm{IC}_{50}\right)$ of 0.59 and $0.68 \mu \mathrm{g}$ $\mathrm{mL}^{-1}$ respectively. The values particularly compare significantly with the antioxidant activity given by vitamin $\mathrm{C}$ (a standard antioxidant drug) at $0.44 \mu \mathrm{g} \mathrm{mL}$ 1 . However, it should be highlighted that the reduced product (J-1) was slightly more active than E-1. From the foregoing, it can be inferred that both reduction and acetylation separately enhance the antioxidant activity of vanillin. Furthermore, J-1 contains the methyl cyclohexyl moiety which confers much more lyphophillic character on the molecule than - $\mathrm{CHO}$, $\mathrm{OCH}_{3}$ and $-\mathrm{OCOCH}_{3}$ in E-1 which could have contributed to the observed antioxidant activity. Other methods apart from DPPH test for determining the antioxidant activity of compounds include the hydrogen peroxide, nitric oxide, conjugated diene, superoxide, phosphomolybdenum, peroxynitrile and xanthine oxidase assay methods amongst many others [22-27].

\section{Conclusion}

This present study shows that the reduced derivative (omethoxy-p-methyl cyclohexan-1-ol) and acetyl derivative (vanillin acetate) elicited significant antioxidant activities. However, the activity demonstrated by reduced product was slightly better than that of the acetyl product.Hence, reduction and acetylation both separately enhances antioxidant activity of vanillin

\section{Consent for Publication}

Not applicable.

\section{Funding}

None.

\section{Conflict of Interest}

The author declares no conflict of interest, financial or otherwise.

\section{Acknowledgements}

The authors acknowledge the kind gesture of the Department of Pharmaceutical and Medicinal Chemistry, University of Uyo for the use of its Jenway 6405UV/VS Spectrophotometer in the antioxidant assays. Also, we are grateful the contribution of the University of Ibadan, Nigeria for the use of its FTIR 84005 Spectrophotometer (Shimadzu, Japan) in obtaining the IR spectra of the compounds.

\section{References}

1. Sies H. Oxidative stress: from basic research to clinical application. The American journal of medicine. 1991 Sep 30;91(3):S31-8.

2. Oladimeji OH, Essien AE, Sheriff AJ, Alemika TE. Evaluation of antioxidant activity of cinnamic acid and some of its derivatives. European Chemical Bulletin. 2019;8(7):224-6.

3. Oladimeji OH, Anwana MA, Attih EE, Effiong DE. 3, 4, 5-Trihydroxycyclohexyl Methanol-A New Reduced Derivative from Structural Activity Relationship Studies (Sars) On Gallic Acid. European Chemical Bulletin. 2020;9(3):103-6.

4. Oladimeji $\mathrm{OH}$, Owere PO, Anthony PC. Acetylation of Cinnamic Acid and Evaluation of Antioxidant Activity of the Resultant Derivative. Biomedical Journal of Scientific \& Technical Research. 2021;39(2):31085-8.

5. B.P., British pharmacopeia, The pharmaceutical press London, appendix VA, A109, 1993, p. 754.

6. Olugbade TA, Adesanya SA. Prieurianoside, a protolimonoid glucoside from the leaves of Trichilia prieuriana. Phytochemistry. 2000 Aug 1;54(8):867-70.

7. Chris IA. Laboratory Organic chemistry techniques qualitative analysis, organic preparations and spectroscopy. Maybinso publishers new Jersey USA. 2010;208:216.

8. Tietze LF, Eicher T, Diederichsen U, Speicher A, Schützenmeister N. Reactions and syntheses: in the organic chemistry laboratory. John Wiley \& Sons; 2015 Jun 22.

9. Bhaskar Kanth JV, PERIASAMY M. Selective reduction of carboxylic acids into alcohols using $\mathrm{NaBH} 4$ and I2. Journal of organic chemistry. 1991;56(20):5964-5.

10. Olaniyi, A. A., Principles of quality assurance and pharmaceutical analysis. Mosuro publishers, 2000, pp. 151-158, 216-217, 264-269 and 443-457.

11. Olaniyi. A. A., Ogungbamila, F. O., Experimental pharmaceutical chemistry. Shaneson C.I. limited, 1991, pp. 49-52.

12. Nagalapur SK, Paramjyothi S. In vitro antioxidant activity of launaea pinnatifida cass leaves. Biogeosciences. 2010;5(1):105-8.

13. Guangrong H, Jiaxin J, Dehui D. Antioxidative and antibacterial activity of the methanol extract of Artemisia anomala S. Moore. African Journal of Biotechnology. 2008;7(9).

14. Lebeau J, Furman C, Bernier JL, Duriez P, Teissier E, Cotelle N. Antioxidant properties of di-tert- 
butylhydroxylated flavonoids. Free Radical Biology and Medicine. 2000 Nov 1;29(9):900-12.

15. Leitão GG, Leitão SG, Vilegas W. Quick preparative separation of natural naphthopyranones with antioxidant activity by high-speed countercurrent chromatography. Zeitschrift für Naturforschung C. 2002 Dec 1;57(11-12):1051-5.

16. Oladimeji $\mathrm{OH}$, Bakare-Odunola MT, Attih EE. Antioxidant Activity of Acalypha wilkesiana var. lace-acalypha (Muell \&Arg.). African Journal of Pharmacology and Therapeutics. 2016 Mar 16;5(1).

17. Rao SR, Ravishankar GA. Biotransformation of protocatechuic aldehyde and caffeic acid to vanillin and capsaicin in freely suspended and immobilized cell cultures of Capsicum frutescens. Journal of biotechnology. 2000 Jan 21;76(2-3):137-46.

18. Nei G, Guan Y, Ying Y, et al. Anti-inflammatory effect of protecatechui aldehyde on myocardial ischemia/reperfusion injury in In-vivo and In-vitro. Inflammation, 2013, 36(3), 592-602.

19. Calixto-Campos C, Carvalho TT, Hohmann MS, Pinho-Ribeiro FA, Fattori V, Manchope MF, Zarpelon AC, Baracat MM, Georgetti SR, Casagrande R, Verri Jr WA. Vanillic acid inhibits inflammatory pain by inhibiting neutrophil recruitment, oxidative stress, cytokine production, and $\mathrm{NF} \kappa \mathrm{B}$ activation in mice. Journal of natural products. 2015 Aug 28;78(8):1799-808.

20. Numpaque MA, González JH, Restrepo DL. Biotransformation of ferulic acid by the phytopathogenic fungi Colletotrichum acutatum and Lasiodiplodia theobromae. Revista Facultad Nacional de Agronomía Medellín. 2016 Jan;69(1):7835-44.
21. Oladimeji $\mathrm{OH}$, Usifoh $\mathrm{CO}$, Attih EE. Novel Antioxidant Activity of Cyathula Prostrata (L.) Blume. European Chemical Bulletin. 2014;3(4):352-7.

22. Burton GW, Ingold KU. $\beta$-Carotene: an unusual type of lipid antioxidant. Science. 1984 May 11;224(4649):569-73.

23. Dapkevicius A, Venskutonis R, van Beek TA, Linssen JP. Antioxidant activity of extracts obtained by different isolation procedures from some aromatic herbs grown in Lithuania. Journal of the Science of Food and Agriculture. 1998 May;77(1):140-6.

24. Jahangir MA, Jain P, Verma R, Taleuzzaman M, Ahsan MJ, Chettupalli AK, Muheem A, Mirza MA. Transdermal Nutraceuticals Delivery System for CNS Disease. CNS \& Neurological Disorders Drug Targets. 2022 Jan 12.

25. Imam SS, Jahangir MA, Gilani SJ, Zafar A, Alshehri S. Nanoemulsions as Delivery Vehicle for Nutraceuticals and Improving Food Nutrition Properties. Nanoemulsions in Food Technology: Development, Characterization, and Applications. 2021 Oct 17:187.

26. Jahangir MA, Taleuzzaman M, Beg S, Verma S, Gilani SJ, Alam P. A Review of Eugenol-based Nanomedicine: Recent Advancements. Current Bioactive Compounds. 2021 Feb 1;17(3):214-9.

27. Jahangir MA, Muheem A, Imam SS, Ahmed FJ, Aqil M. Nigella sativa Encapsulated NanoScaffolds and Their Bioactivity Significance. InBiomarkers as Targeted Herbal Drug Discovery. 2021 Jul 4:155-75.

Copyright: @2022 Oladimeji OH, et al. This article is distributed under the terms of the Creative Commons Attribution 4.0 International License (http://creativecommons.org/licenses/by/4.0/), which permits unrestricted use, distribution, and reproduction in any medium, provided you give appropriate credit to the original author(s) and the source, provide a link to the Creative Commons license, and indicate if changes were made.

(cc) $\mathrm{EY}$ 